\section{Ekpe Inyang}

Ekpe Inyang worked for the World Wide Fund for Nature and Wildlife

Conservation Society, served as a consultant to the German Technical Agency (GIZ) in Cameroon, and is currently the Capacity Building Advisor, and doubles as Education for Sustainable Development Team Leader, of WWF Cameroon. Email: ainyang@wwfcam.org ainyang@yahoo.com

\section{Community theatre as instrument for community sensitisation and mobilisation}

\title{
Community theatre as instrument for community sensitisation and mobilisation
}

Environmental protection, sustainable economic development and good governance are important issues of the century, and theatre can play an important role in addressing them. This paper contends that community theatre is likely to offer a sustainable alternative approach towards addressing these and other current myriad issues confronting the African continent. Recognising that rural communities are proactive agents of change, their exclusion from the design, development and implementation of community theatre activities, coupled with the difficulties in sourcing and securing funding for the promotion of conventional theatre activities, are only a few of the problems likely to be encountered. The paper highlights some of the potential implementation constraints and proposes strategies that could be deployed to effectively develop and establish community theatre as part of the African traditional system with a view to influencing change at all levels of the community in particular and the nation at large. Keywords: African traditional system, community theatre, environmental protection, sustainable economic development.

\section{Introduction}

Environmental protection, sustainable economic development and good governancce are apparently the tripodal platform on which leading global issues of the century are debated. Theatre is increasingly becoming a predominant tool for sensitisation and mobilisation of local comunities for economic, political and environmental development.

Theatre is a folk art which, like any such art, must originate in the community. It can best be developed and communicated to the audience by people who 'speak the same language' with the audience, people who, as Stuart Hall points out, must share sets of concepts, images and ideas which enable them to think and feel, and thus interpret phenomena, in roughly similar ways.

This paper serves to highlight the importance of community theatre with a view to encouraging its development and establishment of such community-based programmes in Africa as a sustainable machinery for addressing the myriad and ever increasing environmental, socio-economic and political problems confronting the continent. It also illuminates some potential implementation constraints and offers ways of overcoming them. 


\section{Theoretical basis of community theatre}

Community theatre is a social activity which, like any other social activity, is inextricably linked with the origins of society itself (Courtney). Courtney adds that a wide range of theatrical presentations are observed in each civilised society, but varies according to the development of the civilisation.

Bertolt Brecht advocated the type of theatre that propels the spectators into action, to bring about the desired change in society, rather than that which plays on their emotions and finally leaves them to take things as they are. In the same vein, Karl Marx held the conviction that although the dominant art would always be that of the dominant class, this does not prevent other sectors or classes from fostering their own art, guided by their own perspectives (Boal).

Dwight Macdonald (60) describes art by non-dominant classes as growing from below; as "a spontaneous, autochthonous expression of the people, shaped by themselves, and without any external influence, to suit their own needs." But this is not to suggest that there should be no involvement of theatre experts because, as Brian Way (1967: 26) notes, "in the early stages of all creative work the participants experience a kind of fear of freedom, which can be a total uncertainty as to what to do; ideas either don't come or are self-rejected as inadequate; there is need for someone to give a start."

For community theatre to be effective, it must not depend entirely on the creativity of 'professional artists' who present to the audience the product of their creative ability derived from the creative imagination of a playwright. While this form of creativity is not discouraged, there are certain shortcomings that must be brought to light. For example, Matthew Arnold in Culture and Anarchy (1869) observes that some artists often try to give the so-called masses intellectual food prepared in the way they think proper for the masses, while others try to indoctrinate the masses with a set of ideas and judgements that constitute the creed of their own professions or parties. Similarly, Augusto Boal in Theatre of the Oppressed (53) reminds us of Karl Marx's argument that spectators receive knowledge "according to the perspective of the artist or of the social sector in which he is rooted, or which sponsors him, pays him, that sector of society which holds the economic power, controlling with it all the other powers and establishing the directives of all creativity." The sponsoring sector, therefore, would be interested mostly in the transmission of knowledge which does not threaten but helps it maintain its power and authority.

\section{Methodological issues in community theatre}

\section{Script-based performances}

Practitioners of community theatre would espouse the involvement and active participation of the community in the development and production of environmental plays. When communities are not involved in the process, environmental 
theatre based on scripts developed by playwrights could hastily be considered as foreign products that should not merit the name of community theatre. This, however, is not the fate, for instance, of the Ngũgí's I Will Marry When I Want (1986) because it is known that a team of recruited community actors developed what was eventually scripted into this fully fledged and highly acclaimed political play. To this I would suggest that to determine whether a play falls in the category of community theatre or not, one must take cognizance not only of where and how the theatre materials used in building the script were generated but also the type, flavour, colour and structure of the materials. Put simply, it would be necessary and expedient to try to answer questions such as: does the theatre also present the views (that is, fears and aspirations) of the community? Does it reflect community life, experience and situation? Does it have the potential to stimulate community debate about the issues raised?

The purpose of an environmental play, like any good play, is to entertain, raise awareness and influence attitude change in ways that should elicit the intended response from the target audiences. To achieve this, an environmental play should be realistic enough to reflect the prevailing circumstances and include not only ecological but also cultural, political and socio-economic interpretations or analyses of the environmental issues raised. This implies the need for a dialectical and creative relationship between the playwright and the target audiences.

The materials used in the development of my environmental plays were derived mostly from information gathered during my routine educational tours of communities. Community meetings, focus group discussions, informal dialogues and observations offered ample opportunities for participatory situation analyses. This method is similar to the one described by Jumai Ewu and Tunde Lakoja as starting from data collection, to story-making, through scenario-development, rehearsals and finally productions of theartre which was employed to resolve an age-long conflict amongst three villages in the Konye area in southwest Cameroon that had maintained their uniqueness despite that they had grown into one village, a situation which had made it impossible for any collective activity to be carried out within the community (Butake, in Eyoh). To save time, only village councillors were used for the improvisation, and they immediately realised that the play was about them as it portrayed their situation so well, and this motivated them to proceed to discussions about solutions. The theatre exercise culminated in not only addressing the issue of disunity but also realising important community development projects, notably replacing a risky hammock with a bridge that links the villages with their farms across a large river.

Though I engaged in the solitary creative process of developing my scripts, the communities can be seen to have played a significant part in the creative process. Perhaps, what is more important and more obvious is the fact that my environmental 
plays were considered mature enough for presentation to communities only after they had been subjected to trial performances in at least two communities. Feedback from the experimental performances provided a basis for incremental development of the plays that were considered ripe for community consumption when the communities start identifying themselves with the theatre situations and get involved, at least emotionally, in the theatre events. One could then feel justifiably confident that the plays could yield the intended results and so could even be published to reach out to wider target audiences.

\section{Hiring a theatre troupe}

As an environmentalist working in protected areas, I had the difficult task of sensitising and educating local communities about conservation and sustainable management of natural resources, since conservation was easily seen as a means of depriving these communities of their sources of livelihhod. The use particularly of community meetings and focus group discussions proved not to be very effective, especially in communities that were hostile to conservation ideas. This led me to try my hand at theatre in 1991 when I wrote my first environmental play Beware (1993) motivated by my hypothesis that theatre could be a more effective instrument for community penetration, sensitisation and mobilisation.

In collaboration with Besong Besong, a literature teacher popularly known as BB, I established a theatre club in Government High School Nguti in southwest Cameroon. We gave some theatre training to the club members and organised them to perform Beware to Nguti and neighbouring communities. The programme was a great success, especially with recorded high attendance rates compared to the number of people who attended community meetings, and this has motivated me to write other environmental plays: The Sacred Forest (1997), The Game and Water na Life (2006), The Last Hope (2011) and The Hill Barbers (2009).

Despite these encouraging results, I faced the problem of having to train new batches of students almost every year. In view of this constraint, I did not hesitate to accept an invitation, in 1995, by a local theatre group, The Forest Pipers of Nguti, who solicited my assistance in building their capacity in the domain of theatre. My conviction was that working with this group was not only going to save me the time and resources required for regularly training new recruits but would also provide an opportunity for establishing a more permanent group. In addition, I thought the arrangement appropriately satisfied my definition of community theatre as "theatre of the community by the community for the community."

The Forest Pipers conducted tours and mounted serval performances of The Sacred Forest and Beware in many communities, especially in the Banyang-Mbo Wildlife Sanctuary area, with tremendous impact. An evaluation of the programme led to some important conclusions that serve to enhance the importance of community theatre, as presented below (Inyang, "Mobilisation”). 
The significance of community theatre

An effective means of communicating sensitive issues

Community theatre an effective way of communicating sensitive issues without the attending antagonism that would have normally occurred in direct realistic situations, a point earlier observed (Eyoh). Despite the fact that some of the messages conveyed by my plays were a direct criticism of local activities and customs that were incompatible with development and conservation goals, the audiences participated actively and positively during the question-and-answer session that followed each theatre performance, as opposed to several cases of hostility that had often greeted community meetings.

\section{A powerful means of engaging community members emotionally}

Theatre presents community members with situations that engage them not only intellectually and aesthetically but also emotionally (Bentley). This type of emotion is best described as "empathy" which Augusto Boal in his Theatre of the Oppressed defines as the emotional relationship established between the character and the spectator, which makes the latter feel the impact of what has happened, is happening, or may happen, to the former. On a number of occasions during my theatre programme at Korup and Banyang-Mbo, some members of the audience were so emotionally involved that they climbed on stage or shouted/cried out passionately in reaction to the renditions or actions on stage.

\section{A powerful tool for stimulating community action}

Theatre is also a powerful way of putting across messages with the aim of stimulating community action to address identified problems and issues. The theatre activities helped to generate positive conservation actions in the targeted communities, with two traditional councils mobilising the male youth to evict foreign hunters from their forest territories. Similarly, five traditional councils passed injunctions against the use of pesticides and dynamite to kill fish, and two voluntarily assisted law enforcement officers in the arrest of culprits. It was also noted that most farmers who watched the theatre performances voluntarily abandoned their traditional method of burning trees on farms indiscriminately and took precautions not to clear farms too close to rivers. Voluntary community actions of this nature were hardly observed when only community meetings were conducted in the villages.

Similarly, in Papua New Guinea, local communities took drastic measures for environmental conservation and entered into better negotiations with timber companies as a result of the conservation messages presented to them through theatre by the Raun Isi Theatre group (Borrini-Feyerabend \& Buchan). This sort of community action was experienced in the Korup project area where some communities 
confronted two timber companies and re-negotiated not only benefits but also the methods and areas of exploitation of their forests.

However, for any theatre piece to achieve its action-inspiring objective, the performance must not take the audience to its 'final' conclusion but should end at a junction of suggests pathways towards expected conclusions. This is summed up by Boal in Theatre of the Oppressed (106) who observed that contrary to the views held by Hegel and Aristotle who advocate "a quiet somnolence at the end of the spectacle [...] Bertolt Brecht wants the theatrical spectacle to be the beginning of action" by the spectator who should seek to transform the society to bring about the needed equilibrium. When the audience expects, for instance, a riot to break out during a performance but does not, the performance has a long-term efficacy as "the 'possible worlds' encountered in the performance are carried back by the audience into the 'real' socio-political world in ways which may influence subsequent action" (Kershaw 28). In other words, the audience is motivated to complete the performance by doing what they feel the performance has left undone. This is similar to Boal's ideology in Legislative Theatre (1998) that the spect-actors in Forum Theatre should transgress, break conventions, enter into the mirror of a theatrical fiction, rehearse forms of struggle and then return to reality with the images of their desires.

\section{A way of giving a voice to the voiceless}

Theatre is a way of giving a voice to the voiceless within the community, in line with Steve Barlow and Steve Skidmore's definition of theatre as an art form that provides individuals with practical opportunities to express themselves and develop aesthetic understanding. Throughout my work in Korup and Banyang-Mbo areas, I realised that theatre offered the only occasion when women and men of low social statuses could speak up freely during village gatherings. This observation is further noted by Eugene van Erven (245) who reports how the Kawuoanda women of Kenya organised into a theatre group and used theatre "to communicate things to men in their community they could not publicly or privately express in any other way."

\section{A sustainable tool for community sensitisation and mobilisation}

Unlike community and other forms of meetings, community theatre provides a sustainable tool for sensitising and mobilising communities. For more than a year after the performance of The Sacred Forest in the Banyang-Mbo area, children and parents alike continued chanting a particular song and repeating some pertinent renditions of some major characters in the play. Furthermore, little children occasionally re-enacted the play as part of their daily activities, sometimes to the entertainment of their parents and other community members. These 'repeater-possibilities' of theatre help keep the messages alive within the communities and can have multiplier effects. Similarly, with additional capacity building and organisation, 
these responses could lead to the eventual incorporation of such theatre activities into the traditional system.

\section{Constraints in the implementation of community theatre Difficulty in securing funding}

There is no activity that does not require funds and community theatre cannot be an exception. A substantial amount of funding is required not only to set up a community theatre but also to monitor and evaluate it. Unfortunately, there is often great difficulty in securing funding to support community theatre activities. It was a huge task for me to convince my project management to continue to support my environmental theatre, even though they were well aware of the positive and great impacts created by the activities. In fact, theatre did not have a place in the project's programme of activities and it was as if I was being given a special favour to carry on in the first place. It was thanks to a community water project funded by Guinness that The Forest Pipers was able to get another three more years of support from the project. This was because Guinness insisted on a sensitisation component to be part of the project, and management saw the need to consider theatre. This supports Eugene van Erven's observation that funding is often available for community theatre if it is part of community development or welfare activities rather than for the promotion of the art per se.

\section{Absence of a common frame of reference}

Starting a community theatre programme can be quite a daunting experience, especially in regard to the orientation of the community members vis-à-vis that of the initiator. Even though I was invited by The Forest Pipers to help build their capacity and reorganise the group, it was a big challenge to bring them to accept using plays different from the ones they were fond of. In fact, the president of the group even asked me to state the benefits the group would enjoy by performing my environmental plays instead of their repertoire of comedies and melodrama that, according to him, not only pulled huge crowds but also provided a source of pride and pleasure for the group. This experience is linked to the absence of a shared frame of reference that Boal in Legislative Theatre identifies as the first problem one confronts when rehearsing theatre with community groups. The theatre group was obviously interested mainly in the entertainment element of theatre whereas my plays emphasised more or less the educational element.

\section{Lack of political support}

Since theatre, by its very nature, also x-rays the society, this can be a source of threat to some people, especially corrupt or oppressive leaders. This situation can make it extremely difficult to initiate or promote a community theatre programme, especially 
as authorisation is often required from an authority in the area for any such activity to be implemented. There were a number of occasions where I was almost refused authorisation to carry out theatre activities but for the intervention of my project management who had to explain further that the activity was part of the programme of a project that was operating under the ministry charged with environmental protection. This was obviously because a chant in The Sacred Forest that was then being performed was seen as not politically favourable: "Bele go before, country go for back." In fact, in one instance, I was accused of sponsoring an illegal political meeting because I was seen offering my theatre players drinks after a very successful rehearsal. This happened when I was in the field for some other assignment, and when I returned I was told by a man of Nguti who shared the drink with us that evening that he was called up for interrogation by the then Assistant Divisional Officer a few days after the meeting.

\section{Making community theatre part of the community}

\section{Forging a culture-sensitive community theatre}

In order for community theatre to be acceptable, or at worst tolerable, the community theatre programme should be sensitive to both the traditional culture and the political culture. This means that the theatre efforts should show some respect for the traditional and political institutions, and must, on no account, fiercely attack these institutions. Rather, community theatre efforts but could subtly advise where there are negative elements within the institutions that genuinely need to be changed.

The order in which issues are tackled may influence the way people perceive the programme and it would be wise to start with issues that almost everyone seeks to address, before moving on to those that are too sensitive to handle. One should bear in mind that because of its ability to sensitise and mobilise the masses to bring about radical reforms, and because of a history of revolutions due mostly to such activities, some traditionalists and politicians might be sceptical about the purpose of any community theatre programmes, unless such programmes are able to demonstrate clearly their aim of resolving the pressing issues that are generally seen to adversely affect the society.

\section{Building the capacity of the community}

Capacity building provides a direct and effective way of improving performance. It should focus on the acquisition of adequate knowledge, cultivation of positive attitudes and development of appropriate skills necessary for action. This can be achieved in workshop settings, with the initial part concentrating on defining, with adequate clarity, the purpose, philosophy and objectives of the community theatre programme. Once these have been established, the workshops can then progress into training in specific skills—such as voice, movement, and groupings-as well as 
technicalities of using selected theatre conventions, and how to monitor and evaluate the impact of the theatre effort.

\section{Promoting the activity}

How can we promote community theatre activities? In other words, how can we ensure that after the training of members and setting up of the community theatre groups the activities will continue without further external drive or support? The answer rests in interest and motivation.

One way of motivating the community theatre groups is to stimulate positive competition amongst them, such as awarding prizes to the best groups. This could be done by organising a competition where various community theatre groups are brought together to perform and/or by taking into consideration the number of performances each group has put on independently, matched with the corresponding results. This is very necessary during the initial stages as part of the monitoring and evaluation process; but it should be noted that continuity of this type of arrangement might be problematic since it requires financial support.

As has been noted earlier, sources of funding, especially for theatre activities, are very limited and the actual amounts given to support such programmes may not be adequate. Some groups usually travel from place to place to carry out their activities, which needs more financial support than most donors might be willing to provide for theatre. Eugene van Erven notes that funding is often available for community theatre if and only when it is part of community development or welfare activities rather than for the promotion of the art per se. In recognition of this difficulty, our intention should be to set up a system whereby each target rural community has its own theatre group to serve it, operating like any other cultural group, in order to guarantee its independence and, therefore, the sustainability of the overall programme.

\section{Monitoring and evaluating the activity}

Monitoring and evaluation is an important, albeit often downplayed, aspect of many field activities. Theatre is an activity that has hardly received any attention when it comes to this phase, and in such a situation its impact cannot be properly assessed. Perhaps, this is where the difficulty with securing funding for theatre activities liesthere must be sufficient proof that the activity is succeeding or is likely to succeed. This can be shown only in a well designed and well implemented programme of monitoring and evaluation which must clearly define what is to be monitored.

Richard Margoluis and Nick Salafsky advise that the specific units to monitor and the appropriate methods of monitoring them should be purposefully selected. To determine what these specific units or indicators are, it requires revisiting the objectives of the community theatre programme. For example, should we be monitoring firstly, community interest in terms of attendance only or should this 
interest be linked with the willingness of community members to support the activity? And secondly, should we be monitoring the number of shows the theatre groups have put on independently only or should this effort be matched with the overall impacts on the communities?

Our answers to the above questions would determine the scope of our monitoring and evaluation programme and also define our monitoring plan. In order to firmly lay claims to the impacts created by our theatre effort, the monitoring and evaluation exercise should be carried out before the theatre programme (to establish the baseline) and then re-measured after each theatre activity (to determine the changes that are occurring).

\section{Conclusion}

Community theatre has a lot of flexibility and offers many opportunities for application in a wide range of contexts. However, this can be both helpful and detrimental. On the one hand, it affords the voiceless and powerless the opportunity to express themselves and act in ways that can contribute meaningfully to the betterment of their community and the society as a whole. On the other hand, the fact that the activity is more or less improvisation-based makes it a rather risky business, and measures need to be taken to ensure that every participant understands and works within the limit of a defined frame of reference.

In the course of developing a community theatre programme, it is advisable to consider the factors that are likely to facilitate or militate against it. It is also necessary to figure out the methods that can be used to take advantage of the facilitating factors and those that can be deployed in order to minimise the effects of the militating factors. This depends on the philosophy and objectives of the programme vis-à-vis the traditional and socio-political context in which the programme is to be implemented.

Funding has been identified as a major constraint for community theatre groups, especially because most of them have to travel from place to place to perform their functions. Setting up a theatre group in each strategic target community to minimise travelling, and making sure that the activities become part of the normal cultural events within the community can be an important strategy for reducing the reliance of groups on external funding and support. As much as possible, funding requests should be made only at the initial stages for the training of group members, for the development of the capacities of the groups to function independently and for the implementation of monitoring and evaluation.

Adequate time should be allocated for the development of the monitoring and evaluation programme, and its implemtation should be systematic, consistent and transparent. The results of the monitoring and evaluation exercises should be communicated not only to the donors and other theatre practitioners but also to the target communities. 


\section{Works Cited}

Arnold, Matthew. Culture and Anarchy. London: C U P, 1869.

Barlow, Steve and Steve Skidmore. Dramaform: A Practical Guide to Drama Techniques. London: Hodder \& Stoughton, 1994.

Bentley, Eric. Life of the Drama. New York: Methuen, 1983.

Boal, Augusto. Theatre of the Oppressed. London: Pluto Press, 1979. . Legislative Theatre, London: Routledge, 1998.

Borrini-Feyerabend, Grazia and Dianne Buchan. Beyond Fences: Seeking Social Sustainability in Conservation Vol. I: A Process Companion. N.P.: World Conservation Union, 1997.

Butake, Bole. "The Kumba Workshop on Th.I.R.D.: Theatre, Conscience and Mobilization: The Re-education of the Community Leaders of Konye Area." Ndumbe H. Eyoh. Hammocks to Bridges: An Experience in Theatre for Development. Yaoundé: BET \& Co Ltd., 1986. 183-98.

Courtney, Richard. Play, Drama and Thought: An Intellectual Background to Theatre in Education. London: Cassell \& Collier Macmillan Publishers Ltd, 1974.

Erven, Eugene van. Community Drama: Global Perspectives. London: Routledge, 2001.

Ewu, Jumai and Lakoju, Tunde. "Unmasking the Masquerades: The Potential of TIE in Nigeria." Learning through Theatre: New Perspectives on Theatre in Education. Ed. T. Jackson. London: Routledge, 1993.

Eyoh, Ndumbe H. Hammocks to Bridges: An Experience in Theatre for Development. Yaoundé: BET \& Co Ltd., 1986.

Hall, Stuart. Representation: Cultural Representation and Signifying Practices. London: Sage, Open U P, 1997. Inyang, Ekpe. "Mobilisation of local communities for conservation: Lessons from the Banyang-Mbo Wildlife Sanctuary in Southwest Cameroon." Ecocultural Perspectives. Eds. Alembong, Nol, Labang Oscar C. and Fombele, Eunice F. Raytown: Ken Scholars Publishing, 2015. 293-310.

. The Sacred Forest. Limbe: Wildlife Conservation Society, 1997.

The Game and Water na Life. Limbe: The Cure Series, 2006.

. The Last Hope. Bamenda: Langaa Publishers, 2011.

The Hill Barbers. Bamenda: Langaa Publishers, 2009.

Beware. New York: Paul-Art Press Inc., 1993.

Kershaw, Baz. The Politics of Performance: Radical Theatre as Cultural Intervention. London: Routledge, 1992.

Macdonald, Dwight. "A Theory of Many Cultures." Mass Culture: The Popular Arts in America. Eds. B. Rosenberg and D. Manning White. New York: Macmillan, 1957.

Margoluis, Richard and Nick Salafsky. Measures of Success: Designing, Managing, and Monitoring Conservation and Development Projects. Washington, D.C.: Island Press, 1998.

Ngũgĩ wa Thiong' o. Decolonizing the Mind: The Politics of Language in African Literature. Nairobi: East African Educational Publishers, 1986.

Way, Brian. Developing through Drama. London: Longman, 1967. 